\title{
Physical activity and Management of Alzheimer's Disease in Tunisian Male Older Adult Patients
}

\author{
Sabri Gaied Chortane ${ }^{1}$, Lazhar Zorgui ${ }^{2}$, Maamer Slimani ${ }^{3}$, \\ Mohamed Dogui ${ }^{4}$, Mohamed Gazzah ${ }^{5}$ and Foued Chéour ${ }^{2}$ \\ ${ }^{1}$ High Institute of Sport and Physical Education of Sfax, Tunisia \\ ${ }^{2}$ High Institute of Applied Biology of Médenine, Tunisia \\ ${ }^{3}$ Faculty of Sciences of Bizerte, Tunisia \\ ${ }^{4}$ Faculty of Medicine of Monastir, Tunisia \\ ${ }^{5}$ Faculty of Sciences of Tunis, Tunisia
}

\begin{abstract}
This study aims to evaluate the effects of physical training on the management of Alzheimer's disease in Tunisian male older adult patients. 21 patients were separate into two groups one of which followed a physical training program for six months and the other served as a control. Our results showed that exercise training significantly manages the cognitive function in patients such as the ADAS total, the ADAS memory and the MMSE. We conclude that physical training could be an interesting approach to the control of Alzeimer's disease in Tunisian male older adult patients.
\end{abstract}

Keywords: Alzheimer's disease; physical activity; older Adult patients

\section{Introduction}

The increase in life expectancy is admittedly nowadays an important gain for humanity, but unfortunately it brings us its procession of degenerative diseases, whose Alzheimer's disease and related dementias. Alzheimer's disease is the major degenerative dementias, induced by aging or by the addition of vascular degenerative diseases or others (Vasile et al., 2008; Smith et al., 2013).

Alzheimer is a disease of the brain. It is characterized by the progressive death of nerve cells with impaired cognitive functions and memory in particular. The causes of this disease are diverse and are often associated with cardiovascular risk factors such as hypertension, diabetes, obesity etc. (Vogel et al., 2006). The management of Alzheimer's disease rests on the medicinal therapy and non medicinal therapy (Friedman and Trappen, 1991; Eggermont et al., 2005). The specific drug therapy includes the acetyl-cholinesterase inhibitions and the antiglutaminergic. They showed a moderate and superior efficacy to placebo on the overall condition of the patient, on cognitive disorders, loss of autonomy and behavioral disorders, but do not prevent the disease to evolve (Vasile et al., 2008). Beyond medicinal taking is poorly evaluated scientifically. Music therapy (Guetin et al., 2007) and physical activity seem both taken into non-medicinal load more developed although still very limited. They seek to fight against two types of consequences of the disease, behavioral disorders such as malnutrition, sleep disorder, anxiety and restlessness etc. and degeneration of cognitive functions (Diesfeldt and Diesfeldt-Groenendijk, 1977; Lindenmuth and Moose, 1990; Friedman and Tappen, 1991; Palleschi et al., 1996; Teri et al., 1998; Arkin et al., 1999; Rolland et al., 2000; Tappen et al., 2000; Eggermont et al., 2005; Scherder and Eggermont, 2006; Williams and Tappen, 2007).

Regular physical activity improves physical fitness aerobic, increases cerebral perfusion and thus allows better oxygenation of the central nervous system (Dustman et al., 1994). Physical activity may thus, for improving the use of oxygen and/or cerebral blood flow, improve the glucose metabolism and the neurotransmitters (serotonin, norepinephrine and dopamine) essential for cognitive functioning. Same, Heyn et al., (2003) and Coelho et al. (2009) have shown physical activity in older that adults with Alzheimer's disease can contribute positively by attenuating decline in cognitive function. However, most studies involving physical activity and Alzheimer disease have used general or aerobic training protocols (Arcoverde et al., 2008; Hernandez et al., 2010). Thereafter, Smith et al. (2013) and Rolland et al. (2000) showed that endurance exercise, walking or cycle ergometer, improved overall cognitive functions assessed by the MMSE and memory capacity as a main factor for the recognition of the level of Alzheimer's disease in older adults.

The objective of this study was to verify the effects of endurance training program on the management of Alzheimer disease in Tunisian male older adult with evaluate some cognitive functions especially memory and intellectual abilities.

\section{Materials and methods}

Patients

This study, which was approved in advance by the Regional Ethics Committee, was carried out on a carefully selected population of 21 Alzheimer patients' adults (63.0 \pm 4.2 years) same education level and this to 
assess the effects of the physical activity on an ergometer cycle and treadmill on the management of Alzheimer's disease and cognitive functions in older adults Tunisian. The patients were randomized into two different groups, training group or wait-list control. The participation was voluntary, anonymous and confidential. Throughout the period of submission to training program, patients followed a life strict hygiene similar.

\section{Physical training program}

Every exercise session was supervised by an exercise physiologist and a nurse practitioner to ensure participants reached their target heart rate. A medicaster was also present onsite in case of emergencies. The physical training program was designed in an effort to ensure the participants met the physical activity guidelines of 150 min per week, as recommended for sedentary adults. The training regimen consisted of three 60 min sessions of aerobic exercise training per week for a period of 12 weeks. The participants' aerobic exercise alternated each session between exercise ergometer cycle and treadmill. The exercise ergometer cycle routine included a $5 \mathrm{~min}$ warm up at 40 watts, cycling for $50 \mathrm{~min}$ at a speed that increased their heart rate to 50$75 \%$ of their maximum achieved heart rate on $\mathrm{VO}_{2} \max$ testing, and a $5 \mathrm{~min}$ cool down at 40 watts. The treadmill workout included a $5 \mathrm{~min}$ warm up at $3 \mathrm{~km} / \mathrm{h}$, walking on treadmill for $50 \mathrm{~min}$ at a speed that increased their heart rate to $50-75 \%$ of their maximum achieved heart rate on $\mathrm{VO}_{2}$ max testing, and a 5 min cool down at $3 \mathrm{~km} / \mathrm{h}$.

\section{Assessment of cognitive functions}

\section{Alzheimer Disease Assessment Scale (ADAS-Cog)}

The cognitive section of the Alzheimer Disease Assessment Scale was the primary outcome measure of the study. The scale consists of 11 brief cognitive tests assessing memory, language, and praxis. Scores range from 0 to70, with higher scores indicating greater severity of cognitive impairment (Rosen et al., 1984).

Mini Mental State Examination (MMSE)

We have evaluated the MMSE of patients before and after training. The MMSE is a brief test (approximately ten minutes) that can be used for screening for cognitive impairment and for estimating severity and progression of Alzheimer's disease and before and after other forms of dementia. The maximum score on the MMSE test is 30. Age and education levels may influence scores. Scores above 20 can suggest mild cognitive impairment, scores between 11 and 20 suggest moderate cognitive impairment and scores of ten or below suggest severe cognitive impairment. These scores are suggested in the context that a patient has already been clinically diagnosed with Alzheimer's disease and a level of cognitive impairment is to be ascertained (Folstein et al., 1975).

\section{Data analysis}

For each cognitive function, the neurophysiologic basic data that are ordinal in nature, ie nonparametric, of the two independents small groups were compared using the Mann-Whitney U test/Wilcoxon Sum Rank test (Chan, 2003). However, for the assessment of the effects of physical treatments for each cognitive function, Wilcoxon Signed Rank test which is appropriate for paired samples was used (Chan, 2003). The two tests for statistical significance were two-tailed and referred to a significance level with $\alpha=0.05$.

\section{Results}

Table 1 shows the basic cognitive state of training and control groups. It defines the overall efficiency measured by the ADAS-Cog test and its subscales such as memory, language and praxis as well as mnemonic skills assessed by the MMSE of the patients. The Mann-Whitney U test showed no significant difference at $\alpha=$ 0.05 between the two groups of patients at the beginning of the rehabilitation program and this for all assessed cognitive functions.

Table 1. Baseline means value \pm SD according to the cognitive function of the two groups Alzheimer's patient participants to the study.

\begin{tabular}{lccc}
\hline Cognitive function & Training group & Control group & Function severity \\
\hline MMSE & $17.83 \pm 4.02$ & $17.00 \pm 5.07$ & Moderate \\
ADAS-Cog total & $37.40 \pm 8.22$ & $37.44 \pm 9.11$ & Moderate \\
ADAS-Cog memory & $19.40 \pm 5.60$ & $19.00 \pm 6.95$ & Moderate \\
ADAS-Cog language & $14.67 \pm 5.31$ & $14.88 \pm 5.06$ & Moderate \\
ADAS-Cog orientation/praxis & $03.23 \pm 2.64$ & $03.56 \pm 3.54$ & Moderate \\
\hline
\end{tabular}

MMSE = Mini Mental State Examination; ADAS-Cog= Alzheimer Disease Assessment Scale-Cognitive Subscale. 
Figures 1, 2 and 3 show the evolution of the ADAS-Cog total, the ADAS-Cog memory and the MMSE of trained patients or no for 6 months with 3 sessions of 60 minutes per week. The ADAS-Cog total and ADASCog memory levels of the training group decreased significantly as confirmed by the Wilcoxon Signed Rank test after a period of physical rehabilitation, while they increase for the control $(\operatorname{Pr} \leq 0.05)$. This indicates that physical training has improved both cognitive functions in patients.

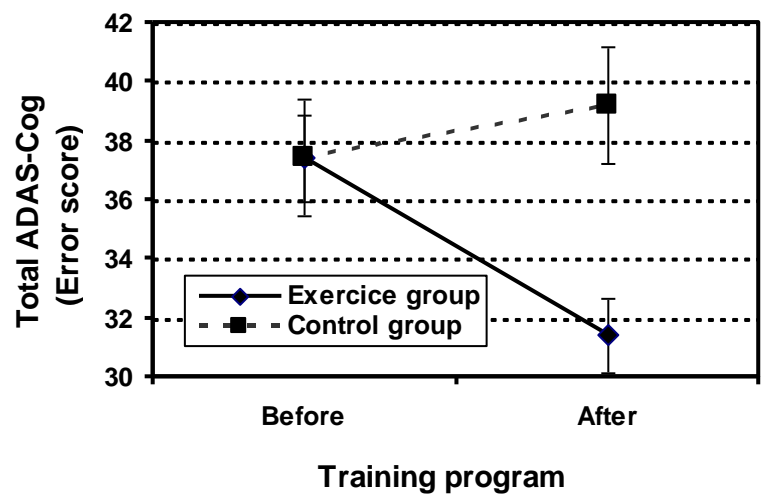

Figures 1. Evolution of the ADAS-Cog total levels in Tunisian male older adult patients belonging to the control group or to the training group that has been submitted to physical rehabilitation program for six months. Mean values \pm SD for $9-11$ patients.

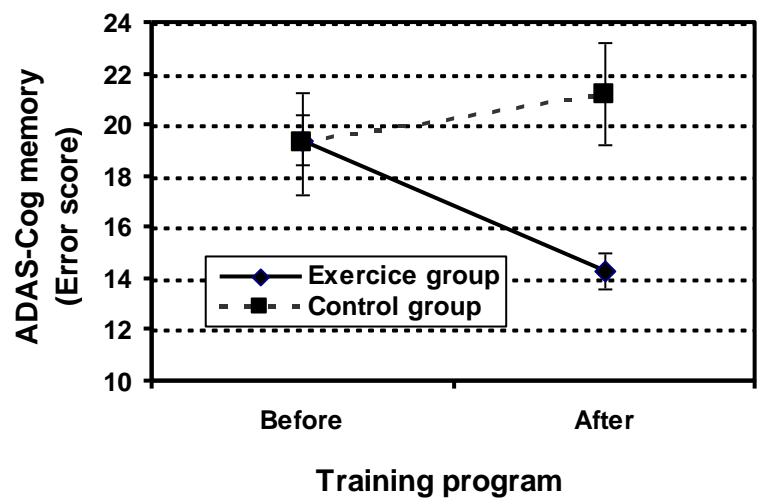

Figures 2. Evolution of the ADAS-Cog memory levels in Tunisian male older adult patients belonging to the control group or to the training group that has been submitted to physical rehabilitation program for six months. Mean values \pm SD for $9-11$ patients.

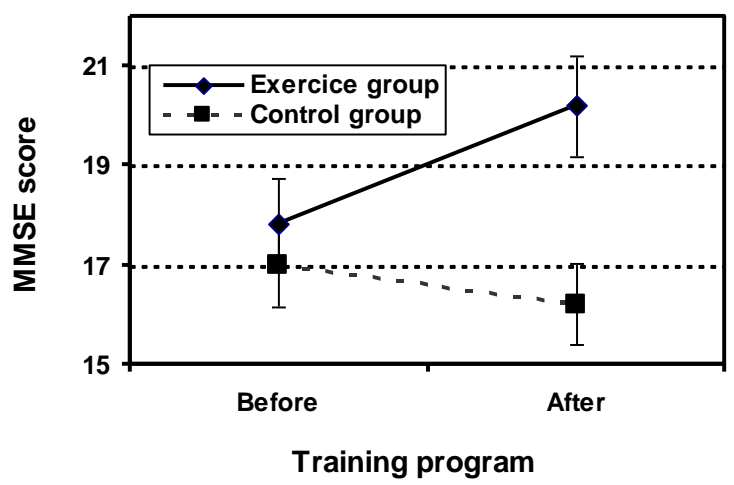

Figures 3. Evolution of the MMSE levels in Tunisian male older adult patients belonging to the control group or to the training group that has been submitted to physical rehabilitation program for six months. Mean values \pm SD for $9-11$ patients.

The MMSE level of the group who was submitted to physical training increases significantly as shown 
by the statistical analysis by the Wilcoxon Signed Rank test after a period of physical rehabilitation, while decreases to that of the control $(\operatorname{Pr} \leq 0.05)$. This indicates that training program improved the MMSE function in patients.

\section{Discussion}

Alzheimer's is a disease that causes an overall slow movement and daily activities. The number of people worldwide suffering from this dementia is estimated at 850,000 with 165,000 new cases per year. Alzheimer's disease and related dementias are a major phenomenon of our modern society. The increasing incidence of this disease is due to two factors. On the one hand, many dementias are tagged Alzheimer's when they meet the same clinical symptoms. Moreover, the prevalence of Alzheimer's disease tends to increase exponentially with the ageing population. It goes from 5\% before 65 to $20 \%$ after 85 years (Anaes, 2001). For the general public, Alzheimer's disease and related dementias are associated with memory disorders or some other cognitive disorders such as memory, behavioural etc. Indeed, the degeneration of cognitive and psychobehavioral mainly defines Alzheimer's disease and related dementias (Colcombe and Kramer, 2003 and 2004; Rovio et al., 2005). Our study showed that physical activity could be a therapeutic mean for Tunisian older adults with Alzheimer's disease and improves multiple aspects of cognitive functioning. This is consistent with results reported in other studies that have shown that physical activity has beneficial effects on cognitive and executive functions, and communication capacity of older people with mild cognitive impairment or dementia of the Alzheimer type (Scherder et al., 2005; Eggermont et al., 2006). Furthermore, Palleschi et al. (1996), Rolland et al. (2000), and Colcombe and Kramer (2003) showed that physical activity types walking, cycling, ergometer. etc. which tend to improve aerobic capacity, as a therapeutic option that can improve cognitive function assessed by the MMSE of older people suffering from senile dementia of the Alzheimer type. Thus, Smith et al. (2013) showed the effect of endurance training on the management of Alzheimer's disease program in older adults with a change in the ADAS-Cog score and its subscales in relation to the care provided usual. ChodzkoZajko et al. (1992) added that fitness was always correlated with memory performance in young and in older people. Although the literature is still poor on the effect of exercise on memory processes of Alzheimer's patients, it appears that a positive impact on memory will be a line of research.

In conclusion, this study shows that physical activity on a cycle ergometer and treadmill used alternately could be an effective method in controlling Alzheimer's disease and improve cognitive states of Tunisian male older adult patients

\section{References}

[1]. Arkin SM. 1999. Elder rehab: a student-supervised exercise program for Alzheimer's patients. Gerontologist, $39: 729-35$.

[2]. Arcoverde C., Deslandes A., Rangel A. 2008. Role of physical activity on the maintenance of cognition and activities of daily living in elderly with Alzheimer's disease. Arquivos de Neuro-Psiquiatria, 66: 323-327.

[3]. Chan Y.H. 2003. Biostatistics 102: Quantitative Data-Parametric and Non-parametric Tests. Sangapore Medicine Journal, 44 : $391-$ 396.

[4]. Coelho FGM., Santos-Galduroz RF., Gobbi S., Stella F. 2009. Ativida de física sistematizada e desempenho cognitivo em idosos com demência de Alzheimer: uma revisão sistematizada. Revista Brasileira de Psiquiatria, 31: 163-170.

[5]. Colcombe S., Kramer AF. 2003. Fitness effects on the cognitive function of older adults: a meta-analytic study. Psychological Science, 14: 125-130.

[6]. Colcombe S., Kramer AF., Erickson KI., Scalf P., McAuley E., Cohen NJ., Webb A., Jerome GJ., Marquez DX., Elavsky S. 2004. Cardiovascular fitness, cortical plasticity, and aging. Proceedings of the National Academy of Sciences of the United States of America, 10: 3316-3321.

[7]. Diesfeldt HFA., Diesfeldt-Groenendijk H. 1977. Improving cognitive performance in psychogeriatric patients: the influence of physical exercise. Age and Ageing, 6: 58-64.

[8]. Dustman RE., Emmerson R., Shearer D. 1994. Physical activity, age and cognitive neuropsychological function. Journal of Aging and Physical Activity, 2: 143-181.

[9]. Eggermont L., Swaab D., Luiten P., Scherder E. 2005. Exercise, cognition and Alzheimer's disease: More is not necessarily better. Neuroscience and Biobehavioral Reviews, 30: 562-575.

[10]. Folstein MF., Folstein SE., Mchugh PR. 1975. Mini-mental state. A practical method for grading the cognitive patients for the clinician. Journal Psychiatry research, 12: 189-198.

[11]. Friedman R., Tappen RM. 1991. The effect of planned walking on communication in Alzheimer's disease. Journal of the American Geriatrics Society, 39: 650-656.

[12]. Guetin S., Portet F., Picot MC., Defez C., Pose C., Blayac JP., Touchon J. 2007. Impact of music therapy on anxiety and depression for patients with Alzheimer's disease and on the burden felt by the main caregiver (feasibility study). Encéphale, 35: 57-65.

[13]. Hernandez SSS., Coelho FGM., Gobbi S., Stella F. 2010. Efeitos de um programa de atividade física nas funções cognitivas, equilíbrio e risco de quedas em idosos com demência de Alzheimer. Revista Brasileira de Fisioterapia, 14: 68-74.

[14]. Heyn P. 2003. The effect of a multisensory exercise program on engagement, behavior, and selected physiological. American Journal of Alzheimer's Disease and Other Dementias, 18: 247-251.

[15]. Lindenmuth GF., Moose B. 1990. Improving cognitive abilities of elderly Alzheimer's patients with intense exercise therapy. American Journal of Alzheimer's Care and Related Disorders and Research, 5: 31-33.

[16]. Palleschi L., Vetta F., Gennaro E., Idone G., Sottosanti G., Gianni W., Marigliano V. 1996. Effects of aerobic training on the cognitive performance of elderly patients with senile dementia of the Alzheimer type. Archives of Gerontology and Geriatrics Supplement, 5: 47-50.

[17]. Rolland Y., Rival L., Pillard F., Lafont C., Riviere D., Albarede JL., Vellas B. 2000. Feasibily of regular physical exercice for patients with moderate to severe alzheimer disease. The Journal of Nutrition, Health and Aging, 4: 109-113. 
[18]. Rolland Y., Pillard F., Klapouszczak A., Reynish E., Thomas D., Andrieu S., Rivière D., Vellas B. 2007. Exercise program for nursing home residents with Alzheimer's disease: a 1-year randomized, controlled trial. Journal of the American Geriatrics Society, 55: $158-65$.

[19]. Rosen WG., Mohs RC., Davis KL. 1984. A new rating scale for Alzheimer's disease. American Journal Psychiatry, 141: 13561364.

[20]. Rovio S., Kåreholt I., Helkala EL., Viitanen M., Winblad B., Tuomilehto J., Soininen H., Nissinen A., Kivipelto M. 2005. Leisuretime physical activity at midlife and the risk of dementia and Alzheimer's disease. Lancet Neurology, 4: 705-711.

[21]. Scherder EJ., Van Paasschen J., Deijen JB., Van Der Knokke S., Orlebeke JF., Burgers I., Devriese PP., Swaab DF., Sergeant JA. 2005. Physical activity and executive functions in the elderly with mild cognitive impairment. Aging and Mental Health, 9: 272-80.

[22]. Smith JC., Nielson KA., Woodard JL., Seidenberg M., Rao SM. 2013. Physical activity and brain function in older adults at increased risk for Alzheimer's disease. Brain Sciences, 3: 54-83.

[23]. Tappen RM., Roach KE., Applegate EB., Stowell P. 2000. Effects of a combined walking and conversation intervention on functional mobility of nursing home residents with Alzheimer's disease. Alzheimer Disease and Associated Disorders, 14: 196-201.

[24]. Teri L., McCurry SM., Buchner DM., Logsdon RG., LaCroix AZ., Kukull WA., Barlow WE., Larson EB. 1998. Exercise and activity level in Alzheimer's disease: a potential treatment focus. Journal of Rehabilitation Research and Development, 35: 411-419.

[25]. Vasile D., Vasiliu O., Ivanov P., Vasile M., Terpan M. 2008. Alzheimer dementia associated cognitive and non-cognitive symptoms evolution during Donepezil treatment. European Psychiatry, 23: 199.

[26]. Vogel T., Athanase Benetos A., Verreault R., Kaltenbach G., Kiesmann M., Marc Berthel M. 2006. Facteurs de risque de la maladie d'Alzheimer : vers une prévention? La Presse Médicale, 35: 1309-1316.

[27]. Williams CL., Tappen RM. 2007. Effects of exercise on mood in nursing home residents with Alzheimer's disease. American Journal of Alzheimer's Disease and Other Dementias, 22: 389-397. 